\title{
Clinical and some biochemical variations with trials of treatment in hypomagnesaemia in buffaloe calves at Assiut Governorate
}

\author{
H. Z. Rateb ${ }^{1^{*}}$, M. E. Radwan ${ }^{2}$ \\ ${ }^{1}$ Department of Animal Medicine Faculty of Veterinary Medicine \\ Assiut University, Assuit,Egypt.. \\ ${ }^{2}$ Animal Health Research Institute, Assiut Regional Laboratory,Assuit,Egypt.
}

\begin{abstract}
A total number of 30 buffaloe calves aged between 1-6 months with body weight range of 100$125 \mathrm{~kg}$ and belonged to private farms at Assiut Governorate constituted the materials of this study. Twenty of them showed the classical signs of hypomagnesaemia while the other ten buffaloe calves were proved to be healthy by both clinical and laboratory methods of examinations and used as control.

Biochemical analysis of blood sera showed a significant hypomagnesaemia, hypocalcaemia and hypophosphataemia in diseased buffaloe calves when compared with the healthy ones, also fluctuation between the previous studied parameters either pre and post treated animals were evident. Meanwhile, blood serum total protein, albumin, globulin, albumin/globulin ratio and GOT levels were fluctuated in diseased buffaloe calves or treated one when compared with the healthy control animals. Statistical analysis between studies parameters were carried out in buffaloe calves before and after treatment.
\end{abstract}

Magnesium is considered to be the major intracellular divalent cation and it is an essential element among a number of the enzymatic activities in the body. Hypomagnesemic tetany occurs in calves 2-4 months of age or older ones which are fed diet of whole milk and calves receiving the greatest quantity of milk and growing rapidely are more likely to be affected (Radostite et al.,2003).

The clinical signs of hypomagnesemic tetany in calves were hyperirritability of the nervous system and development of tetany which terminated in spasticity, opisthotonus and a violent convulsions. During convulsions respiratory movements may be abolished and a characteristic passage of the nictitating membrane across the eye balls are noticed in calves. Irregular respiration, accelerated pulse rate, elevated body temperature, congested mucus membrane, engorged eye capillaries and intense heart sounds are also recorded (Attia,1999; Radostits et al.,2003).

Hypomagnesemic tetany has been observed in

\footnotetext{
* Corresponding author. (H. Z. Rateb)
}

calves from three months of age and upword when fed an exclusive milk diet (Udall,1992). Calf tetany resulted when the amount of magnesium in the diet is inadequate for the requirments of the calf and the efficiency of magnesium absorption from intestine will decrease markedly up to three months of age when the maximum susceptipility to the disease occurs especially those fed milk replacer or whole milk, concentrates or hay and calves running at pasture with their dams (Radostits et al.,2003). Smith (1996) reported that, milk tetany occurred in calves that were raised indoors entirely on milk low in magnesium but since absorption of magnesium is excellent in neonates signs of hypomagnesemia does not occur until 2-4 months of age when absorption has decreased.

The clinical signs of calf tetany are started by stiff walking, nervousness as well as great susceptibility to muscular twitching and fright combined with spasmodic muscular contractions of limbs and neck muscles partly opened with mouth. The terminal tetanic stage are preceded by ataxia, hyperaesthesia, opisthotonus and convulsions. The hypomagnesemic tetany in 
calves are often complicated in field cases by the coexistence of other diseases specially enzootic muscular dystrophy. (Udall, 1992; Smith, 1996; Radostits et al.,2003).

In clinically affected calves with hypomagnesemic tetany, the blood serum magnesium level was usually less than $1 \mathrm{mg} / \mathrm{dl}$ and associated with hypocalcaemia. Also, the blood serum calcium level was below normal $(5-8 \mathrm{mg} / \mathrm{dl})$, serum phosphorous may be lowered and there was marked increase in serum asparte aminotransferease (Udall, 1992; Smith, 1996; Radostits et al.,2003). Smith (1996) and Jayanthi et al., (1997) added that the blood serum magnesium level decreased to less than $1.2 \mathrm{mg} / \mathrm{dl}$ and increased serum aspartate aminotransferase and hypocalcaemia, hypophosphataemia were recorded.

Elimination and control for reduction of hypomagnesemic tetany in calves had been tried by many authors and most of them concluded that the best treatment is combination of magnesium, phosphorous and calcium salts (Bacon et al., 1990; Doherty and Mulville, 1992; Udall, 1992; Smith, 1996; Attia, 1999; Radostits et al., 2003)..

Preventive measures could be taken to reduce the incidence of hypomagnesemic tetany in calves include supplementary feeding of magnesium with magnesium oxide or magnesium sulfate in drinking water and vitamin D (70.000 IU vit. D3/day), (Smith, 1996; Wittwer et al., 1997; Attia, 1999; Radostits et al., 2003).

Blood serum proteins have many important physiological functions to the animal body. They maintain normal blood volume, osmotic pressure, haemostasis, resistance to infection and help in absorption of many minerals such as calcium, phosphorus and various nutrients. Albumin is the most abundant of plasma proteins that is readily the avilable pool of amino acids needed to tissue and has an important transport function (Schalm,1986; Attia,1999). Aspartate amino transferase has a wide distribution in animal tissues and present in small quantities in the serum as a results of normal tissue destruction and subsequent enzyme release, that reflected to cellular destruction (Attia,1999).

This study amied to through light upon clinical and some biochemical alteration in buffaloe calves suffered from hypomagnesaemia associated with trials of treatement.

\section{Material and Methods}

Animals. A total number of 20 buffaloe calves their age varied from 1-6 months, body weight ranged between 100-125 $\mathrm{kg}$ body weight and belonged to private farms at Assiut Governorate were suffered from hypomagnesemic tetany and showed stiffiness in gait associated with hyperirritability of the nervous system and development of tetany with spasticity, opisthotonus and violent convulsions constituted the material of this study. These animals were fed on whole milk, receiving the greatest quantity of milk and some of them put on intensive rapid rearing system of fattening.

Another 10 clinically healthy buffalo calves used as a control. These animal related to private farms and were subjected to careful clinical and laboratory examination to ensure their health status.

Blood samples. Two blood samples were obtained from each animals by a jugular vein puncture without anti-coagulant before and after treatment to obtain sera for biochemical studies.

Biochemical tests. Determination of magnesium, calcium and phosphorus were performed using test-kits after the methods described by (Bohuon, 1962; Goldenberg, 1966; Gindler, 1972). Determination of Aspartate amino transferase has been estimated using testkits as described (Reitman and Frankel, 1957). Determination of total protein and albumin using test-kits as described (Frank, 1950; King and Wootton,1959)and serum globulin and albumin globulin ratio were calculated mathematically.

Treatments. The diseased animals were treated using the following treatement:

1- Injection of Cofacalcium (COOPHAVET) intravenously $150 \mathrm{cc}$ and $50 \mathrm{cc}$ subcut in three successive days.

2- Magnesium sulphate 20\% (C.P.EVANS .EGYPT.Co), $200 \mathrm{ml}$ by rectal enema for three successive days.

3- Norflex ampoule (EIPICO) two ampoules were given daily for three successive days as skeletal muscles relaxant.

4- injection of Ringer solution (El-Nasser) containing $\mathrm{Na}, \mathrm{K} \& \mathrm{Cl}$ was given intravenously in $500 \mathrm{ml}$ for 3 days.

5- Magnesium sulphate powder (El-Nasser) 30 gm added to rations daily for 15 days.

Statistical analysis. The obtained results were analysed statistically according to (Selvin, 1996).

\section{Results}

Clinical symptoms. The most important clinical signs in diseased buffaloes were stiffness in gait associated with hyperirritability of the nervous system and development of tetany 
Table 1. Biochemical analysis of blood serum magnesium, calcium and phosphorus levels in hypomagnesemic buffaloe calves before and after treatment.

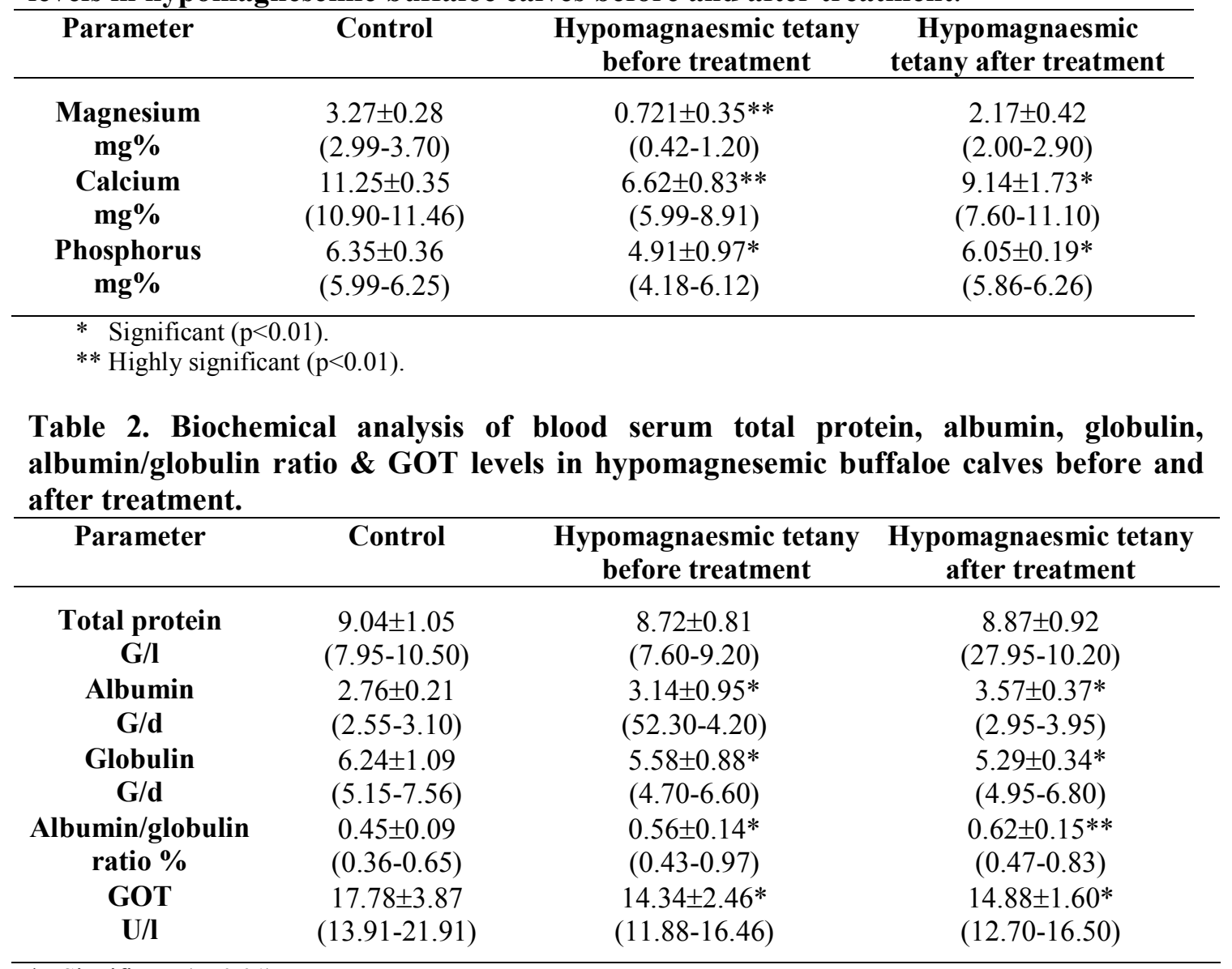

which terminated in spasticity, opisthotonus and violent convulsions. The respiration temporarily abolished, the nictitating memberan across the eye balls has been noted in the calves. Also most cases revealed irregular respiration, accelerated pulse rate and elevated body temperature. Congested mucus membrane, engorged eye capillaries and intense heart sounds were noticed (Fig.1). Calves were recovered and convulsions disappeared after the adminestration of specific therapy which was described before (Fig.2).

Biochemical analysis of blood serum magnesium, calcium and phosphorous of young buffaloe calves suffering from hypomagnesemic tetany showed a significant decrease when compared with the healthy ones. Statistical analysis between pre and post treated animals are also illustrated (Table, 1). Biochemical analysis of blood serum total protein, albumin, globulin, albumin/globulin ratio and GOT of young buffaloe calves suffering from hypomagnesemic tetany showed a fluctuation (Trable 2).

\section{Discussion}

Magnesium is considered to be the major intracellular divalent cation, and essential for enzymatic activities in the body. Owing to the intensive fattening veals calves were susceptible to some nutritional disturbances including hypomagnesaemia during neonatal life.

The most important clinical signs in diseased buffaloes were stiffness in gait associated with hyperirritability of the nervous system and the development of tetany which terminated in spasticity, opisthotonus and violent convulsions. The respiration temporarily abolished, the nictitating memberan across the eye balls has been noted in the calves. Most cases revealed irregular respiration, accelerated pulse rate elevated body temperature. Congested mucus membrane, engorged eye capillaries and intense heart sounds. These clinical signs were coincided with that previously mentioned by (Udall, 1992; Smith, 1996; Attia, 1999 and Radstits et al.,2003). This may be attributed to central effect 


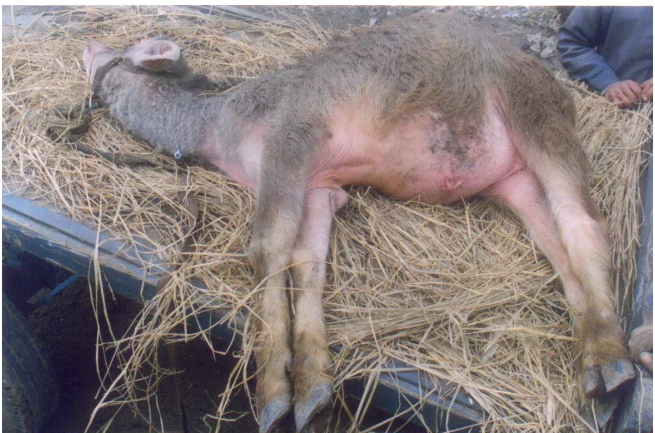

Fig.1 Tetanic convulsions associated with dorsal flexion of the head and neck in diseased buffalo calve.

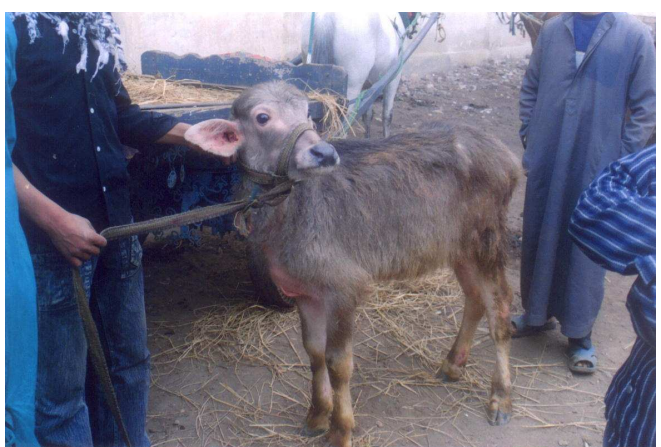

Fig.1 Recovered buffalo calve after treatment and disappearance of clinical findings.

of magnesium on the nervous system by activating choline estrase which breakes down acetyl choline, therefore central nervous system was in a hyperirritable state during magnesium deficiency. Biochemical analysis of blood serum magnesium, calcium and phosphorous of young buffaloe calves suffering from hypomagnesemic tetany showed a significant decrease in pretreated animals compared with the treated ones, which reached $0.72+0.35 \mathrm{mg} \%, 6.62+0.83 \mathrm{mg} \%$ and $4.91+0.97 \mathrm{mg} \%$ respectively. Diseased animals showed significant decrease in the levels of magnesium, calcium and phosphorus comparing with the healthy ones. Similar findings were recorded by (Udal, 1992; Smith, 1996; Attia, 1999; Radostits et al., 2003), who coincided that a concurrent hypocalcemia with hypomagnesaemia may have a contributing effect and in many instances may be the dominant factor of hypomanesemia. The absorption ability of magnesium decrease with increasing the age from eight to fourteen weeks where high susceptibility to diseases occur. There was a relationship between dam's and their newly born calves serum magnesium concentration (Smith, 1996; Attia,1999; Radostits et al.,2003). Moreover magnesium deficiency may influence calcium homostasis, hypomagnesaemia associated with hypocalcaemia. Biochemical analysis of blood serum total protein, albumin, globulin, albumin/globulin ratio and GOT of young buffaloe calves suffering from hypomagnesemic tetany showed a fluctuation. These results are present in acute or chronic cells damage, as magnesium is mainly an intracellular cation and is known to be required for the activation of large number of enzymes in the animal body (Smith, 1996; Singh et al., 1996 ; Attia, 1999; Radostits et al.,2003).

Trials of treatment of diseased buffaloe-calves allivate the clinical signs of hypomagnesaemia and elevated the levels of studied parameters in treated calves to be assumed arround the normal obtained levels in buffalo-calves.

\section{References}

Attia, M. T. A. (1999): Some studies on hypomagnesaemia in calves under natural and experimental conditions. M.V.Sc. Fac. Ved. Med., Zagazig Univ., Egypt.

Bacon, J. A.; Bell, M. C.; Miller, J. K.; Ramsey, N. and Muller, F. J. (1990): Effect of magnesium administration route on plasma minerals in Holstein calves reciving either adequate or insufficient magnesium in their diet. J. Dairy Sci., 73: 470-473.

Bohuon, C. (1962): Colorimetric determination of magnesium. Anal. Chem. Acta. 7: 811-817.

Doherty, T. J. and Mulville, J. P. (1992): Diagnosis and treatment of large animal diseases. $1^{\text {st }}$ ed. W.B.Saunders Company, Philadelphia, London, Tornto, Montreal, Sydney and Tokyo.

Frank, H. U. (1950): Photometric analysis of albumin and globulin in serum. Dtsh. Arch. Klin. Med. 197: 181.

Gindler, M. (1972): Colorimeteric determination of serum calcium. Am. J. Clin. Path. 58: 376-382.

Goldenberg, H. (1966): Colorimeteric determination of serum phosphorus. Clin. Chem. 12: 871

Jayanthi, M.; Sundar, S. N.; Karunanidhi, P. S. and Chaudhuri, P. C. (1997): Serum biochemical findings in experimental hypomagnesaemia in buffalo calves. Ind. Vet. J. 74 (9): 752-754.

King, E. J. and Wootton, I. (1959): Microanalysis in medical biochemistry. Churchill, London.

Radostits, O. M; Blood, D. C.and Gay, C. C. (2003): Vet. Medicine, A text book of the diseases of cattle, sheep, pigs, goats and horse. $10^{\text {th }}$ ed. Bailliere Timdall pp.1727.

Reitman, S. and Frankel, S. (1957): Colorimeteric determination of GOT and GPT activity. Am. J. Clin. Path. 28: 56 .

Schalm, O. W. (1986): A Text Book of Physiology. $5^{\text {th }}$ ed. Lea and Febiger, Philadelphia USA.

Selvin, w. (1996): Statistical analysis of Epidemiological Data, $2^{\text {nd }}$ ed. Oxford Univ. pp.44-78.

Singh, O. V.; Shukla, S. K. and Kumar, M. (1996): Clinico-haematological and biochemical changes in experimental hypomagnesaemia in buffaloe calves. Int. J. Anim. Sci. 11 (2): 313-317.

Smith, B. P. (1996): Large Animal Internal Medicine. $2^{\text {nd }}$ ed. Mosby Year Book, Inc. USA.

Udal, R. H. (1992): The practice of veterinary medicine. $3^{\text {rd }}$ Indian ed. Oxford and IBH, New Delhi. 
Wittwer, F.; Contreras, P. A.; Silva, N. and Bottmwald, H. (1997): Effects of magnesium supplements as magnesium oxide in food or magnesium sulfate in water on the prevention of hypomagnesemic tetany and blood and urine magnesium concentrations in hypomagnesemic hereford calves. Archivos de Medicina Veterinaria 29 (1): 25-33.

\section{الأعراض الاكلينيكيه وبعض التغيرات البيوكيميائيه و محاولات للعلاج لحالات نقص الماغنسيوم في عجول الجاموس}

$$
\text { بمحافظة أسيوط }
$$

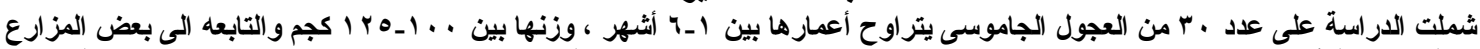

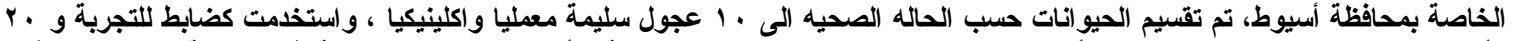

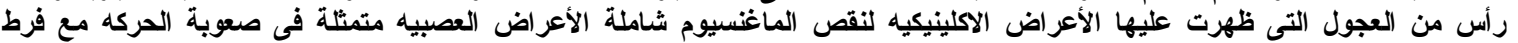

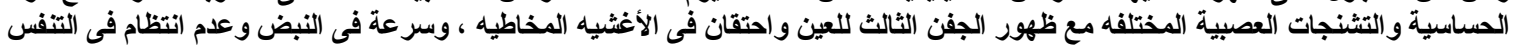

واحتقان فى شعير ات العين.

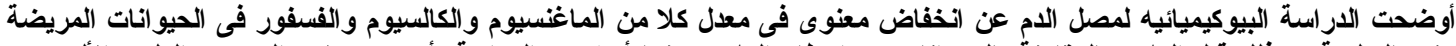

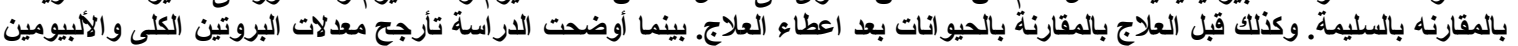

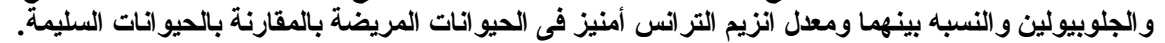

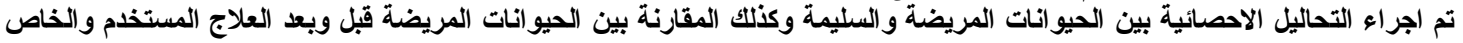

